\title{
ON SOME OBJECTIONS TO THE DEDUCTIVE CLOSURE OF LEGAL SYSTEMS
}

\author{
Hugo R. Zuleta \\ University of Buenos Aires \\ hugo.r.zuleta@gmail.com
}

SUMMARY: I criticize an argument presented by Pablo Navarro and Jorge Rodríguez (2014) against the conception of legal systems as sets of statements closed under logical consequence. First, I show that the example on which they ground their argument incurs in a fallacy of equivocation. Then, I recognize that the authors are right about the fact that two different normative bases can react differently to changes, but I claim that that is not a decisive reason for choosing always the expressly enacted norms as the system's basis, that the selection of the best basis should be guided by methodological considerations and that, to that purpose, it is necessary to consider the whole set of logical consequences as part of the system.

KEY WORDS: axioms, consequences, dynamics, descriptions, consistency

RESUMen: Critico un argumento presentado por Pablo Navarro y Jorge Rodríguez (2014) contra la concepción de los sistemas jurídicos como conjuntos de enunciados cerrados por la relación de consecuencia lógica. Muestro primero que el ejemplo en que basan su argumento incurre en una falacia de equívoco. Luego reconozco que los autores tienen razón al afirmar que dos bases axiomáticas diferentes pueden reaccionar de manera distinta ante los cambios, pero sostengo que ello no es una razón decisiva para elegir siempre como base del sistema las normas promulgadas expresamente, que la selección de la mejor base debe estar guiada por consideraciones metodológicas y que ello requiere considerar al conjunto de las consecuencias lógicas como parte del sistema.

PALABRAS CLAVE: axiomas, consecuencias, dinámica, descripciones, consistencia

\section{Introduction}

As it is well known, Alchourrón and Bulygin conceive of legal systems as kinds of deductive systems, i.e. sets of statements closed under the relation of deductive consequence, and define a legal order as a sequence of legal systems such that each of the members of the sequence can be justified by the rules existing in the previous system of the sequence.

Navarro and Rodríguez (2014) challenge this conception. ${ }^{1}$ In their view, it is better, in order to explain legal dynamics, to consider only the expressly enacted norms as members of the legal systems. They don't deny the importance of taking into account the deductive

${ }^{1}$ P. Navarro and J.L. Rodríguez, 2014, Deontic Logic and Legal Systems, Cambridge University Press, New York. 
consequences of the enacted norms to the effect of identifying which rules are implicitly derogated by an act of legislation, but claim that it is better not to consider them as members of the system.

They argue, in the first place, that in a deductive system it is important to distinguish between the axiomatic basis and the derived statements, and that this distinction is not possible if legal systems are defined in the way Alchourrón and Bulygin do because the same system can have different axiomatic bases. The reason adduced for the importance of the distinction is that two extensionally equivalent axiomatic systems with different bases can react differently when an inconsistency is introduced into the system by the enactment of a new norm. In their view, this feature of axiomatic systems justifies taking the rules enacted as the axiomatic basis. They conclude that considering the logical consequences as members of the system is neither necessary nor convenient.

I agree with Navarro and Rodríguez about the importance of distinguishing the axiomatic basis from the other logical consequences, but I think that the example with which they try to justify their view is fallacious. On the other hand, I consider that the fact that two extensionally equivalent systems with different bases can react differently when a new norm is introduced is not a sufficient reason for always choosing the enacted norms as axiomatic bases.

In the second section I present Navarro and Rodríguez's example. In the third section I prove that the example is invalidated by a fallacy of equivocation. In the fourth section I show that it is true that different axiomatic bases can react differently to changes, but I argue that this fact is not a sufficient reason to prefer taking as a basis the rules enacted, because sometimes there are methodological reasons for choosing a different basis. I conclude that it is necessary to consider the legal systems as closed under logical consequence in order to decide which basis is the best.

\section{The Example}

In order to establish the importance of distinguishing between the axiomatic basis and the other deductive consequences of a legal system, Navarro and Rodríguez present the following argument:

it may occur that the same normative act produces, as a result, a logical indeterminacy over one axiomatic base but not over another with identical logical consequences [... ] Suppose normative authorities have enacted two formulations, one of which admits two possible interpretations: 
$\mathrm{NF}_{1}$ : "Buenos Aires is the capital of Argentina."

$\mathrm{NF}_{2}$ : "The President of Argentina must reside in the place indicated in the previous norm."

$\mathrm{NF}_{2}$ is ambiguous, because the clause "The place indicated in the previous norm" can be read as a reference to the capital of Argentina or to the city of Buenos Aires, what leads to these two different normative bases:

$\mathrm{NS}_{1}$ :

$\mathrm{N}_{1}$ : Buenos Aires is the capital of Argentina.

$\mathrm{N}_{2}$ : The President of Argentina must reside in the capital of the Republic.

$\mathrm{NS}_{2}$ :

$\mathrm{N}_{1}$ : Buenos Aires is the capital of Argentina.

$\mathrm{N}_{2}^{\prime}$ : The President of Argentina must reside in Buenos Aires.

These two interpretations are logically equivalent because they have the same consequences. [In $\mathrm{NS}_{1}$ both sentences together imply $\mathrm{N}_{3}$ : "The President must reside in Buenos Aires." In $\mathrm{NS}_{2}$ both sentences together imply $\mathrm{N}_{3}{ }^{\prime}$ : "The President must reside in the capital of the Republic."] However, they are not identical, because the enactment of a new norm such as:

$\mathrm{N}_{4}$ : The President of Argentina must reside in Mar del Plata,

will lead to indeterminacy regarding which is the new system in the sequence if we take into account the first set of norms but not the second, because in the latter $\left(\mathrm{NS}_{2}\right), \mathrm{N}_{4}$ clearly will result in the derogation of $\mathrm{N}_{2}{ }^{\prime}$ by application of the principle lex posterior (assuming all norms are at the same level in the hierarchy). As both sets of norms react differently to the same normative act, there has to be some difference between them. Nevertheless, this difference is not extensional, because the logical consequences of both sets are equivalent, but intensional.

On the interpretation that each momentary system is closed under logical consequence, all bases with the same logical consequences become equivalent, in the sense that any reformulation of the normative base with the same logical consequences should be accepted. In our case, if $\mathrm{NS}_{1}$ and $\mathrm{NS}_{2}$ are two normative bases that have identical consequences, because $\operatorname{Cn}\left(\mathrm{NS}_{1}\right)=\mathrm{Cn}\left(\mathrm{NS}_{2}\right)$, they should be considered as two different presentations of the same system, and the law at time $t$ will be equally constituted by either of them. But then the difference the example exposes will remain unexplained. (pp. 229-230)

Navarro and Rodríguez advance three theses:

a) It is important to distinguish between the basis of a system and the other logical consequences. 
b) For that reason, it is convenient to restrict the notion of "legal system" to finite bases.

c) The finite bases are to be constituted by the enacted norms.

While I agree with the first thesis, I think that the example on which they ground it is fallacious. On the other hand, I think that theses b) and c) are not justified by a), as they seem to maintain.

\section{The Fallacy}

The above example is fallacious, because, contrary to Navarro and Rodríguez's claim, systems $\mathrm{NS}_{1}$ and $\mathrm{NS}_{2}$ are not extensionally equivalent, since the definite description "the capital of the Republic" is used in two different ways in $\mathrm{NS}_{1}$ and $\mathrm{NS}_{2}$. So, $\mathrm{N}_{2}$ and $\mathrm{N}_{3}^{\prime}$ are different norms and, as a consequence, the systems have different logical consequences.

In order to prove my contention, it is necessary, in the first place, to recall that a definite description can be used in two different ways, which have been called "referential" and "attributive" respectively.

When a definite description is used in a referential way, it behaves like a name. This means that its reference is fixed and it can be substituted for any name or definite description of the same object in any context salva veritate.

By contrast, when the expression is used in an attributive way, it doesn't behave as a name and, therefore, there are some contexts in which it cannot be substituted for any name or definite description of the same object salva veritate.

For instance, let's take the sentence: "John desires to marry the most beautiful woman in the town." It is possible to interpret this sentence in two different ways:

Interpretation 1:

John has already decided whom he desires to marry and, as it happens, that woman is actually the most beautiful in the town.

Let's suppose that the woman's name is Ethel. Then, the substitution of "Ethel" for the definite description "the most beautiful woman in the town", that results in the sentence "John desires to marry Ethel," does not affect the truth value. Both sentences are extensionally equivalent. 


\section{Interpretation 2:}

John has not decided to marry any particular woman. His desire is to marry whoever happened to be the most beautiful woman in the town.

In this case, the substitution of "Ethel" for the definite description will produce a change in the truth value of the resulting sentence, because it is not true that John desires to marry Ethel, since he has not formed the intention of marrying any particular woman.

Now, in the system $\mathrm{NS}_{1}$, the description "the capital of the Republic" that appears in norm $\mathrm{N}_{2}$ must be interpreted as attributive because, if it were interpreted as referential, it should be considered as an alternative way to refer to Buenos Aires. Then, the incorporation of $\mathrm{N}_{4}$ would not result in any indeterminacy, since it would be impossible to restore consistency by the abrogation of $\mathrm{N}_{l}$. That is so because $\mathrm{N}_{2}$ would still be referring to Buenos Aires, in plain contradiction with $\mathrm{N}_{4}$.

In contrast, when the definite description is interpreted as attributive, the sentence means that, whatever happens to be the capital of the Republic, the president must reside there, and so, it implies, among other sentences:

$\mathrm{N}_{5}$ : "If the capital of the Republic is Mar del Plata, the President must reside in Mar del Plata",

$\mathrm{N}_{6}$ : "If the capital of the Republic is Tucumán, the President must reside in Tucumán",

[...] $\mathrm{N}_{n}$ : "If the capital of the Republic is Neuquén, the President must reside in Neuquén."

It is for that reason that it becomes compatible with norm $\mathrm{N}_{4}$ when $\mathrm{N}_{1}$ is abrogated, and so, it is possible to restore consistency either by the abrogation of $\mathrm{N}_{1}$ or of $\mathrm{N}_{2}$.

On the other hand, the same expression must be understood as referential in the derived norm $\mathrm{N}_{3}{ }^{\prime}$ : "The President must reside in the capital of the Republic" of system $\mathrm{NS}_{2}$, because norms $\mathrm{N}_{1}$ and $\mathrm{N}_{2}^{\prime}$ do not imply that whatever happened to be the capital of the Republic, the President must reside there. As a consequence, norms $\mathrm{N}_{5}$ to $\mathrm{N}_{n}$ do not belong to $\mathrm{NS}_{2}$. 
4. The Importance of Distinguishing the Axiomatic Basis from the Derived Norms

Although in the previous section I proved that Navarro and Rodríguez's example is fallacious, in this section I argue that it is true that two different axiomatic bases of the same deductive system can react differently to the enactment of a new norm.

Consider the following example:

$\mathrm{N}_{1}$ : It is obligatory that $p(O p)$,

$\mathrm{N}_{2}$ : It is obligatory that $q(O q)$,

$\mathrm{N}_{3}$ : It is obligatory that $p$ and $q(O(p . q))$,

$\mathrm{N}_{4}$ : It is obligatory that $p$ if and only if $q(O(p \equiv q))$,

where " $p$ " and " $q$ " stand for sentences that describe actions.

According to standard deontic logic, the system can be axiomatised in more than one way; for instance:

$\mathrm{NS}_{1}$ : The axioms are $\mathrm{N}_{1}$ and $\mathrm{N}_{2}$, while $\mathrm{N}_{3}$ and $\mathrm{N}_{4}$ are derived norms. $\mathrm{NS}_{2}$ : The only axiom is $\mathrm{N}_{3}$, while $\mathrm{N}_{1}, \mathrm{~N}_{2}$, and $\mathrm{N}_{4}$ are derived norms. $\mathrm{NS}_{3}$ : The axioms are $\mathrm{N}_{2}$ and $\mathrm{N}_{4}$, while $\mathrm{N}_{1}$ and $\mathrm{N}_{3}$ are derived norms.

Now suppose that a new norm is enacted to the effect that the omission of $p$ be allowed:

$\mathrm{N}_{5}$ : It is permitted that not $p(P \neg p)$.

In order to restore consistency, in $\mathrm{NS}_{1}$ it is enough to eliminate $\mathrm{N}_{1}$ and, as a consequence, also the derived norms $\mathrm{N}_{3}$ and $\mathrm{N}_{4}$. So, the new system will be composed by $\mathrm{N}_{2}$ and $\mathrm{N}_{5}$.

In contrast, in $\mathrm{NS}_{2}$ it is necessary to eliminate the axiom $\mathrm{N}_{3}$ because it implies $\mathrm{N}_{1}$, which is incompatible with $\mathrm{N}_{5}$. But, as $\mathrm{N}_{2}$ and $\mathrm{N}_{4}$ also derive from $\mathrm{N}_{3}$, they will also have to be eliminated and so, the resulting new system will be composed by $\mathrm{N}_{5}$ only.

Now, I think that it is very reasonable to adopt as a methodological principle one that establishes that we should prefer the axiomatic basis that preserves more norms when some of them must be eliminated in order to restore consistency. Let us call it "principle of minimal loss".

So, contrary to Navarro and Rodríguez, I consider that it is not always sound to identify the axiomatic basis of a system with the enacted norms, because there can be good methodological reasons to prefer a different basis. 
At this point it is important to emphasize that I am not contending that "minimal loss" is the only or the best criterion, but I consider it as a reasonable one. My reason for defending it is that I think that, generally speaking, it is in accordance with the practice of legal scholars and judges. When a new law proves to be incompatible with a clause of some preexistent law, for instance an article of a code, we usually consider that that clause, but not the whole statute, has been abrogated. Of course, as any principle, it only gives pro tanto reasons to act in a certain way and may occasionally be overridden by other criteria.

It must also be noted that the principle of minimal loss is not univocal. It cannot decide between $\mathrm{NS}_{1}$ and $\mathrm{NS}_{3}$, for instance. On the other hand, in case the axiomatic basis were $\mathrm{NS}_{3}$, it would be possible to restore consistency either by dropping $\mathrm{N}_{2}$ or $\mathrm{N}_{4}$. Hence, this axiomatization leads to an indeterminacy regarding which the new system is. But this is not a sufficient reason to dismiss it. On the contrary, there may be good reasons to adopt it; for instance, the interpreter could consider that dropping $\mathrm{N}_{2}$ and keeping $\mathrm{N}_{4}$ reflects the legislator's intention more faithfully than other alternatives.

I think that the selection of the best axiomatic basis is part of the task of legal scholars. But in order to be able to choose among different possible axiomatic bases of a system it is necessary to consider the system as closed under logical consequence.

In other words, to explain legal dynamics consists of explaining the passage from one momentary system to a different momentary system.

Now, if legal systems were conceived in the way proposed by Rodríguez and Navarro, i.e. if they only contained the axiomatic basis, and not its logical consequences, it would not be possible to explain the passage from the momentary system that contains only norm $\mathrm{N}_{1}$ :

$\mathrm{N}_{1}: O(p \cdot q)$

to the momentary system that contains these two norms, when $\mathrm{N}_{4}$ is enacted:

$\mathrm{N}_{3}: O q$

$\mathrm{N}_{4}: P \neg p$

because it is necessary, to that purpose, to change the basis of the first momentary system to: 
$\mathrm{N}_{2}: O p$

$\mathrm{N}_{3}: O q$

but that is impossible if norms $\mathrm{N}_{2}$ and $\mathrm{N}_{3}$ do not belong to the system, and, as a consequence, the methodological principle of minimal loss cannot be satisfied. ${ }^{2}$

Received: September 21, 2015; accepted: May 12, 2016.

${ }^{2}$ I am very grateful to Jorge L. Rodríguez, Ezequiel Monti, and Andrej Kristan, whose comments and criticisms led me to revise and expand many passages. I am also indebted for helpful suggestions made by an anonymous referee of Crítica. 